\title{
A multidisciplinary approach to scars: a narrative review
}

\author{
This article was published in the following Dove Press journal: \\ Journal of Multidisciplinary Healthcare \\ 12 August 2015 \\ Number of times this article has been viewed
}

\section{Emiliano Zanier ${ }^{1,2}$ \\ Bruno Bordoni, ${ }^{1,3}$ \\ 'AITOP (Accademia Italiana Terapia Osteopatica Posturale), Castelvetro (MO), Italy; ${ }^{2}$ EdiAcademy, Milan, Italy; ${ }^{3}$ Department of Cardiology, Santa Maria Nascente Institute IRCCS, Don Carlo Gnocchi Foundation, Milan, Italy}

Correspondence: Bruno Bordoni Department of Cardiology, Santa Maria Nascente Institute IRCCS, Don Carlo Gnocchi Foundation, Via Capecelatro 66, Milan, Italy Email bordonibruno@hotmail.com

\begin{abstract}
The purpose of this article is to carry out a narrative review regarding the approach to scars through complementary and alternative medicine focusing on osteopathy, naturopathy, and other minor methods and traditional rehabilitative medicines, such as physiotherapy and manual therapies. We analyzed the existing literature regarding the possible influences of techniques relaxing the diaphragm - both manual and psychophysical relaxing techniques - and the consequent local response to events leading to scar tissue healing. The objective of the study is to become a useful instrument of knowledge for those manual therapists and professionals who deal with patients affected by discontinuity of the skin surface due to trauma or surgery. This article also intends to stimulate research in order to find and propose new methods of scar treatment, taking into consideration the information gained so far from other complementary and alternative disciplines.
\end{abstract}

Keywords: scar, wound, complementary and alternative medicine, osteopathy, naturopathy

\section{Psyche and its influence on scar tissue healing: relaxation techniques, expressive writing, and hypnosis}

There are several hypotheses regarding the alteration of the scar tissue healing processes. ${ }^{1}$ The main types of scars related to nonphysiological healing processes are keloids (K), hypertrophic scars (HSs), and atrophic scars. ${ }^{1}$ Currently, there are many hypotheses, including the theory of neurogenic inflammation, explaining the altered biochemical events that produce scars, which are considered treatable. ${ }^{2}$ According to some authors, these assumptions could confirm the importance of the psychological effect on scar tissue healing. ${ }^{3}$ The effects of stress on the alteration of inflammatory parameters, through the mediation of the hypothalamic-pituitary-adrenal (HPA) axis, are well known. ${ }^{2}$ It has already been demonstrated how restraint and social disruption can activate the HPA system in a different manner, resulting in the increase of corticosterone in the plasma as a response to the proinflammatory cytokines, a phenomenon observed in wound healing process. ${ }^{3}$ Recently, Pyter et $\mathrm{al}^{4}$ have shown how different mechanisms related to stress (ie, physical restraint and social isolation) can equally affect wound healing, although with different methods and timing. In an animal model, the administration of oxytocin, a hormone linked to social contact, could positively or negatively affect wound healing depending on the stimulus given. ${ }^{5}$ According to Furtado et al, ${ }^{6}$ psychological stress should be recognized as a risk factor for $\mathrm{K}$ recurrence in patients who have undergone surgery in order to hinder the formation of $\mathrm{K}$. 
These mechanisms of action related to oxidation are still not fully explained by the existing literature.

According to some authors, skin symptoms, such as itching and pain associated with scars, are associated with the presence and synthesis of neuropeptides govern the patterns of cutaneous reinnervation, inflammation, and wound healing. ${ }^{7}$ This phenomenon is further corroborated by the fact that the use of the hyperbaric chamber can improve wound healing in stressed animals by increasing the level of oxygen in the wounds. ${ }^{8,9}$ Moreover, the mechanism by which the relaxation strategies, which involve diaphragmatic breathing or meditation, directly influence the oxidation mechanisms should be emphasized. ${ }^{10,11}$ With reference to the oxidative stress, which is the result of tissue oxygenation, the effect of diaphragmatic activity should be analyzed from a vascular and lymphatic perspective as well (as described in our previous work). This could lead to multidisciplinary integration between psychological therapy, relaxation techniques, and osteopathic therapy. ${ }^{12,13}$

With reference to the neurocognitive approach, Koschwanez et $\mathrm{al}^{14}$ have emphasized the role of expressive writing (a form of therapy that uses writing to facilitate the communication of the posttraumatic emotional state) in increasing the rapidity of reepithelization, without any changes to perceived stress, depressive symptoms, health-related behaviors, lipopolysaccharide-induced proinflammatory cytokine production, or the number of medical visits over the study period. ${ }^{14}$ In this study, the authors have assumed that psyche may be involved in the wound healing process in a way that has not been fully explained from a psychological and biological point of view. ${ }^{14}$

Hypnosis has been proven to accelerate the process of wound healing after surgery. ${ }^{15}$ Hypnosis has also been shown to be useful in the management of wounds originating from burns, as well as for painful symptoms. ${ }^{16} \mathrm{~A}$ study by Berger et al showed that a protocol in pain management including hypnosis reduced patient anxiety and exposure to pain; increased early opioid delivery; and decreased general anesthesia requirements, length of hospital stay, and costs. ${ }^{16}$

\section{Mechanical and manual rehabilitative approaches to scars}

Manual medicine, physiotherapy, and osteopathy are some of the manual rehabilitative approaches to treat scars. Although most professionals commonly use these techniques, there is little peer-reviewed literature on these techniques.

Occupational therapy mainly consists in reeducating the patient who had suffered from skin damage due to surgery or burns, whether it be an adult or a child. ${ }^{17}$ Motion techniques are used to reeducate patients and bring them back to selfsufficiency, because very often, skin injuries result in the loss of motor patterns acquired previously, thus preventing an individual from being autonomous. ${ }^{17}$

Literature is divided in the evidence that supports massage therapy in the treatment of scars. Some studies have reported good results, such as less pain and itching, and massage therapy was found to be effective in the presence of scars and burns. ${ }^{18}$ However, some studies concerning the use of massage in analogous pathological circumstances have reported inconsistency in achieving effective results. ${ }^{19}$ Thus, there are dissenting views in literature with regard to the use of massage and further studies are needed.

The cupping therapy, which has its origin in Chinese medicine, consists in creating a vacuum inside a small cup - which can be made of bamboo, glass, bakelite, or plastic (always through suitable equipment) - lying on the skin surface of the scar or next to it. According to the professionals who apply this technique, it enables the disposal of toxins and of any potential edema and restores the lymphatic circulation, with consequent effects even in areas that are far from the zone of application. Although there are several studies regarding the application of this technique, further studies are needed in order to undoubtedly affirm its effectiveness. ${ }^{20}$ However, it is important that this technique is used by experienced professionals, because such practices could impede the improvement of the scar itself. ${ }^{21}$ Among its many applications, acupuncture is also used in the treatment of scars and plays an important role in the correct healing process. ${ }^{22}$ The needles may be connected to low-level voltage or various mixtures of seasonings and spices can be applied to the needles. ${ }^{22}$

A similar therapy is dry needling or dry-needle technique, which uses very thin needles on an area considered painful or fibrotic, without medication; the objective of the technique is to loosen tissues, enabling the various layers to slide over each other. ${ }^{23}$ Currently, there is very little literature regarding symptomatic treatment of scars, but the results look promising. ${ }^{24}$

Connective tissue massage; deep transverse friction massage, also known as Cyriax deep transverse massage (Figure 1); shiatsu; crochetage; and diacutaneous fibrolysis are used by many professionals in the treatment of the scar tissues. However, currently, there is no peer-reviewed literature concerning the application of these techniques to skin areas that are not intact.

Literature does not report the use of indirect osteopathic techniques for the treatment of scars (Figure 2), although 


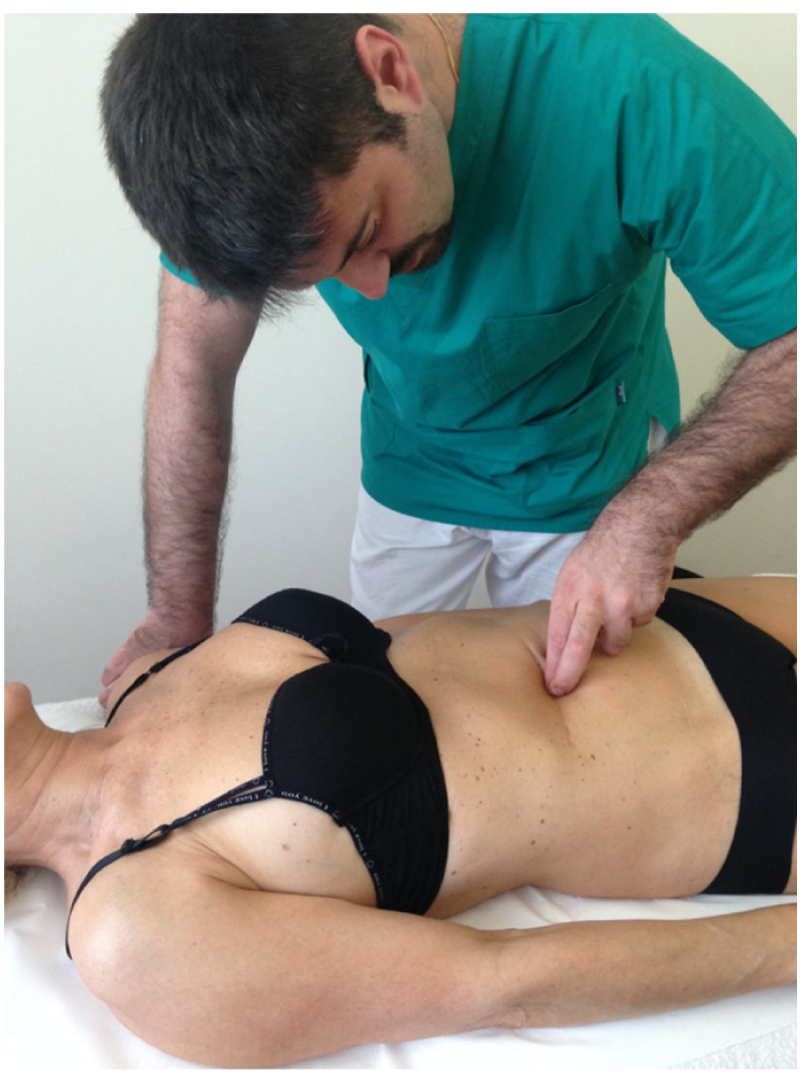

Figure I Cyriax deep transverse massage.

Note: DTFM, also known as Cyriax deep transverse massage, helps to limit the nonphysiological evolution of scars.

Abbreviation: DTFM, deep transverse friction massage.

these techniques are intended to loosen tissues, ie, to release the skin and the underlying layers. As already reported in various scientific studies, this results in the resetting of the peripheral neurological information (afferents). ${ }^{25}$

\section{Naturopathic and herbal approach to scars}

Some plants are indicated as particularly interesting in the herbal and naturopathic tradition. Recently, Läuchli et al have proposed the treatment of scars on the head with exposed skull bone, with a mixture of hypericum oil (Hypericum perforatum L.) and neem oil (Azadirachta indica), reporting a reduction in the time of healing and consequently a reduction of medical costs. ${ }^{26}$ It must be emphasized that the authors do not compare the use of honey with a surgical procedure, which could considerably reduce the treatment times. ${ }^{26}$ This mixture of hypericum oil (H. perforatum L.) and neem oil (A. indica) was applied to major lesions on the diabetic foot as well as in the treatment of burns in children. ${ }^{27,28}$ Other plants such as Rosa mosqueta (Rosa aff. rubiginosa) are recommended for topical use in the treatment of scars. ${ }^{29} R$.

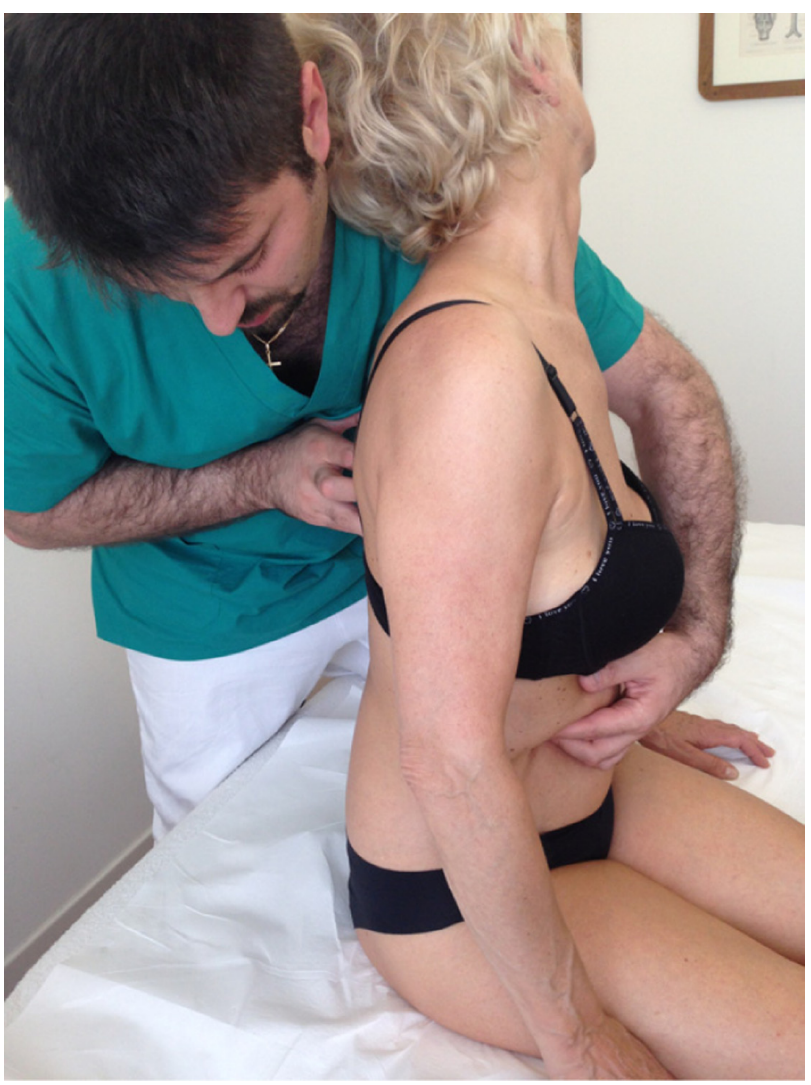

Figure 2 Indirect osteopathic techniques.

Notes: These techniques allow a therapist to follow a tissue in its preferential direction, far from the restrictive barrier of inherent motion. The therapist puts the hand on the skin allowing it and the subcutaneous layers to guide the palpation.

mosqueta ( $R$. aff. rubiginosa) would be particularly helpful in reducing inflammation and therefore the altered cell proliferation observed in $\mathrm{K}$ and $\mathrm{HS}^{29}$ On the other hand, R. mosqueta ( $R$. aff. rubiginosa) seemed to be helpful in encouraging the proliferation phase and the cell regeneration phase during wound healing. ${ }^{29}$ With regard to medicinal plants used in case of burns, Bahramsoltani et al highlighted how garlic (Allium sativum), Aloe vera, Centella asiatica, and Hippophae rhamnoides can improve the healing of burns. ${ }^{30}$

Some Ayurvedic treatments are noteworthy, which are reported in various articles. The application of Madhu (honey) is very effective for the management of Vrana (wounds), which is considered as a potent antibacterial, anti-inflammatory, antiviral, and antioxidant element. ${ }^{31-33}$ Site of the wound, shape, size, floor, and margin were recorded in the healing process and till the end of the healing for the progression of granulation, scar type, shape, size, and clinical symptoms. There was significant improvement in the healing process as honey possesses antibacterial, wound cleansing, and wound healing properties, and it showed beneficiary effects. ${ }^{31}$ According to Al-Waili et al, wound healing properties 
of honey include stimulation of tissue growth, enhanced epithelialization, and minimized scar formation. ${ }^{32}$ These effects are ascribed to honey's acidity, hydrogen peroxide content, osmotic effect, nutritional and antioxidant contents, stimulation of immunity, and unidentified compounds. ${ }^{32}$ Prostaglandins and nitric oxide play a major role in inflammation, microbial killing, and healing process, and honey seems to be a regulator of these elements. ${ }^{32}$ Also, Yaghoobi et al have shown that honey has antioxidant, antibacterial, and anti-inflammatory properties. ${ }^{33}$

Another important plant from the Ayurvedic tradition is "Tulsi" (Ocimum sanctum) ${ }^{34}$ Tulsi is an aromatic shrub of the basil family Lamiaceae (tribe Ocimeae) and grows natively throughout the Eastern world tropics. ${ }^{35}$ This herb, with its multiple effects, can lead to an increase in wound-breaking strength and accelerate wound healing. ${ }^{34,35}$

\section{Conclusion}

When there is an alteration in the healing process, phenomena that are less physiological, such as the formation of $\mathrm{K}$, HS, and atrophic scars, can occur. How to manage scars? This is still an open question in modern medicine as there are no specific protocols and studies based on significant numbers. Literature also reports therapeutic possibilities in complementary and alternative medicine, which could be taken more into consideration. However, there are no scientific and unquestionable data that can be referred to. It has to be noticed that biomedical studies have improved medical treatment in the last 2 decades, and now alternative medicine should move to evidence-based medicine. Research on the treatment of scars should make a greater effort to broaden therapeutic cognizance and well-being of the patients. Overall, for the treatment to be successful, a stronger cooperation of different professionals and the application of different medical disciplines would be advisable.

\section{Acknowledgment}

The authors would like to thank Philippe Caiazzo, the founder of AITOP (Accademia Italiana Terapia Osteopatica Posturale) and all the staff of AITOP, for the friendship, and the support in preparing this manuscript.

\section{Disclosure}

The authors report no other conflicts of interest in this work.

\section{References}

1. Bordoni B, Zanier E. Skin, fascias, and scars: symptoms and systemic connections. J Multidiscip Healthc. 2013;7:11-24.
2. Akaishi S, Ogawa R, Hyakusoku H. Keloid and hypertrophic scar: neurogenic inflammation hypotheses. Med Hypotheses. 2007;1(1):32-38.

3. Sheridan JF, Padgett DA, Avitsur R, Marucha PT. Experimental models of stress and wound healing. Wound J Surg. 2004;28(3):327-330.

4. Pyter LM, Yang L, McKenzie C, et al. Contrasting mechanism by which social isolation and restraint impair healing in male mice. Stress. 2014;17(3):256-265.

5. Detillion CE, Craft TK, Glasper ER, Prendergast BJ, DeVries AC. Social facilitation of wound healing. Psychoneuroendocrinology. 2004;29(8):1004-1011.

6. Furtado F, Hochman B, Farber PL, Muller MC, Hayashi LF, Ferreira LM. Psychological stress as a risk factor for postoperative keloid recurrence. J Psychosom Res. 2012;72(4):282-287.

7. Henderson J, Terenghi G, McGrouther DA, Ferguson NM. The reinnervation pattern of wounds and scars may explain their sensory symptoms. J Plast Reconstr Aesthet Surg. 2006;59(9):942-950.

8. Gajendrareddy PK, Sen CK, Horn MP, Marucha PT. Hyperbaric oxygen therapy ameliorates stress-impaired dermal wound healing. Brain Behav Immun. 2005;19:217-222.

9. Tsvetkov EA, Verevitin AG, Grinfel'd IaL, Veĭnberg TG. Hyperbaric oxygenation in the postoperative treatment of children with cicatricial laryngostenosis. Vestn Otorinolaringol. 1990;(4):44-47.

10. Martarelli D, Cocchioni M, Scuri S, Pompei P. Diaphragmatic breathing reduces exercise-induced oxidative stress. Evid Based Complement Alternat Med. 2011;2011:932430.

11. Maharita C. Roles of meditation on alleviation of oxidative stress and improvement of antioxidant system. J Med Assoc Thai. 2010; 93(Suppl 6):S242-S254.

12. Bordoni B, Zanier E. Anatomic connections of the diaphragm: influence of respiration on the body system. $J$ Multidiscip Healthc. 2013;6: 281-291.

13. Rusak A, Rybak Z. New directions of research related to chronic wound healing. Polim Med. 2013;43(3):199-204.

14. Koschwanez HE, Kerse N, Darragh M, Jarrett P, Booth RJ, Broadbent E. Expressive writing and wound healing in older adults: a randomized controlled trial. Psychosom Med. 2013;75(6):581-590.

15. Ginades C, Brooks P, Sando W, Jones C, Aker J. Can medical hypnosis accelerate post-surgical wound healing? Results of a clinical trial. Am J Clin Hypn. 2003;45(4):333-351.

16. Berger MM, Davadant M, Marin C, et al. Impact of a pain protocol including hypnosis in major burns. Burns. 2010;36(5):639-646.

17. Heath K, Timbrell V, Calvert P, Stiller K. Outcome measurement tools currently used to assess pediatric burn patients: an occupational therapy and physiotherapy perspective. J Burn Care Res. 2011;32(6):600-607.

18. Cho YS, Jeon JH, Hong A, et al. The effect of burn rehabilitation massage therapy on hypertrophic scar after burn: a randomized controlled trial. Burns. 2014;40(8):1513-1520.

19. Shin TM, Bordeaux JS. The role of massage in scar management: a literature review. Dermatol Surg. 2012;38(3):414-423.

20. Cao H, Li X, Liu J. An updated review of the efficacy of cupping therapy. PLoS One. 2012;7(2):e31793.

21. Birol A, Erkek E, Kurtipek GS, Kocak M. Keloid secondary to therapeutic cupping: an unusual complication. J Eur Acad Dermatol Venereol. 2005;19(4):507.

22. Hunter J. Acupuncture for keloid scar. Acupunct Med. 2011;29(1):2.

23. Cagnie B, Dewitte V, Barbe T, Timmermans F, Delrue N, Meeus M. Physiologic effects of dry needling. Curr Pain Headache Rep. 2013;17(8):348.

24. Cummings M. Myofascial pain from pectoralis major following transaxillary surgery. Acupunct Med. 2003;21(3):105-107.

25. Valouchová P, Lewit K. Surface electromyography of abdominal and back muscles in patients with active scars. $J$ Bodyw Mov Ther. 2009; 13(3):262-267.

26. Läuchli S, Vannotti S, Hafner J, Hunziker T, French L. A plant-derived wound therapeutic for cost-effect treatment of post-surgical scalp wounds with exposed bone. Forsch Komplementmed. 2014;21(2):88-93. 
27. Labichella ML. The use of an extract of Hypericum perforatum and Azadirachta indica in advanced diabetic foot: an unexpected outcome. BMJ Case Rep. 2013;2013.pii:bcr2012007299.

28. Mainetti S, Carnevali F. An experience with paediatric burn wounds treated with a plant-derived wound therapeutic. J Wound Care. 2013; 22(12):681-682.

29. Santos JS, Vieira AB, Kamada I. Treatment of open wounds using Mosqueta Rose: a review. Rev Bras Enferm. 2009;62(3):457-462.

30. Bahramsoltani R, Farzaei MH, Rahimi R. Medicinal plants and their natural component as future drugs for the treatment of burn wounds: an integrative review. Arch Dermatol Res. 2014;306(7):601-617.

31. Vijaya KK, Nishteswar K. Wound healing activity of honey: a pilot study. Ayu. 2012;33(3):374-377.
32. Al-Waili N, Salomon K, Al-Ghamdi AA. Honey for wound healing, ulcers, and burns; data supporting its use in clinical practice. Scientific WorldJournal. 2011;11:766-787.

33. Yaghoobi R, Kazerouni A, Kazerouni O. Evidence for clinical use of honey in wound healing as an anti-bacterial, anti-inflammatory, antioxidant and anti-viral agent: a review. Jundishapur J Nat Pharm Prod. 2013;8(3):100-104.

34. Cohen MM. Tulsi - Ocimum sanctum: a herb for all reasons. JAyurveda Integr Med. 2014;5(4):251-259.

35. Singh S, Taneja M, Majumdar DK. Biological activities of Ocimum sanctum L. fixed oil - an overview. Indian J Exp Biol. 2007;45: $403-412$.
Journal of Multidisciplinary Healthcare

\section{Publish your work in this journal}

The Journal of Multidisciplinary Healthcare is an international, peerreviewed open-access journal that aims to represent and publish research in healthcare areas delivered by practitioners of different disciplines. This includes studies and reviews conducted by multidisciplinary teams as well as research which evaluates the results or conduct of such teams or

\section{Dovepress}

healthcare processes in general. The journal covers a wide range of areas and welcomes submissions from practitioners at all levels, from all over the world. The manuscript management system is completely online and includes a very quick and fair peer-review system. Visit http://www.dovepress.com/testimonials.php to read real quotes from published authors.

Submit your manuscript here: http://www.dovepress.com/journal-of-multidisciplinary-healthcare-journal 